\title{
Practice
}

\section{Interactive case report \\ An alcoholic patient who continues to drink: case outcome}

Stuart McPherson, Colin John Rees

This is the final part of a three part case report, which describes the outcome and summarises the comments made by readers during the case presentation. Further responses are welcome through bmj.com

Department of Gastroenterology, South Tyneside Healthcare NHS Foundation Trust South Shields NE34 OPL

Stuart McPherson specialist registrar Colin John Rees consultant gastroenterologist

Correspondence to: C J Rees

Colin.rees@ sthct.nhs.uk

BMJ 2006;332:276-9
Four weeks ago (7 January BMJ 2006;332:33) we presented the case of Mr Bond, who has a history of alcoholic cirrhosis and presented with a variceal bleed. He discharged himself four days after admission and went home to stay with his girlfriend (14 January BMJ 2006;332:98). He was stable for a few weeks, but when reviewed in clinic he admitted to continued alcohol consumption. At this time he was strongly advised to work towards complete abstinence and was given advice about the local alcohol services available to him. Mr Bond had not contacted these as he felt that they would not help. Mr Bond was clear that he planned to continue to drink, although aiming for a reduced level. We therefore felt that acamprosate, which can help to reduce alcohol cravings in some patients, ${ }^{1}$ would not be helpful. Mr Bond was aware that he had severe alcoholic liver disease and that his prognosis with continued drinking was very poor.

Mr Bond presented to our unit two months later with a further variceal bleed. This was successfully treated with injection sclerotherapy and he remained in hospital for 10 days. Measures to prevent further bleeding were considered. Measures available include avoidance of alcohol, drug prophylaxis, obliteration of varices with endoscopic sclerotherapy, or banding and insertion of a transjugular intrahepatic portosystemic stent shunt. ${ }^{2}$ Although the shunt is very effective, the view of the regional liver unit during his admission was that an elective procedure to insert a shunt was inappropriate because $\mathrm{Mr}$ Bond continued to drink alcohol to excess and his bleeding had stopped. We were advised that should he have further bleeding his case should be discussed again.

\section{How far should treatment go?}

Mr Bond represents a good example of a common problem encountered in our gastroenterological practice. Wider moral questions are raised about how far we go with the care of patients whose condition is due to their lifestyle. Similar issues could be discussed in relation to many other areas of health care-for example, people who continue to smoke or misuse drugs. Recent high profile cases of alcoholic patients undergoing liver transplantation have widened this debate to the media and general public.

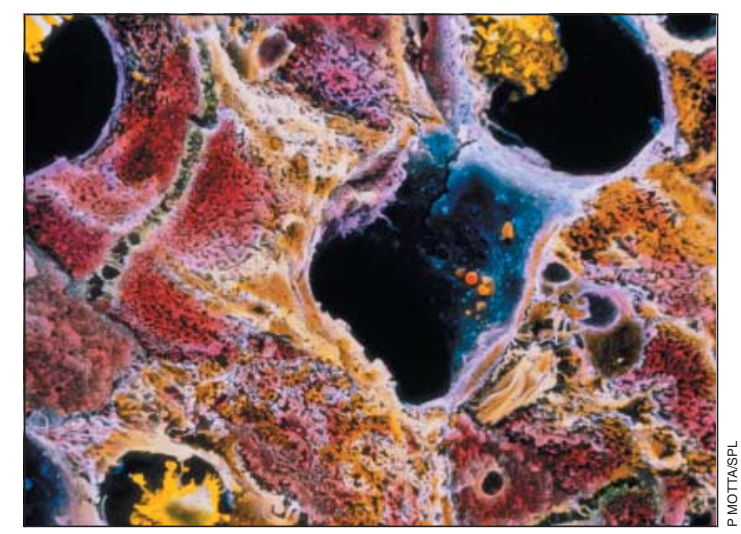

False colour scanning electron micrograph of cirrhotic liver

In our experience, clinicians' treatment of alcoholic patients varies hugely. How aggressively patients are managed may depend on which unit a patient is admitted to or on which team is on call that day. Within our unit, colleagues have differing opinions about how far treatment should go in alcoholic patients, particularly those with recurrent admissions. It seems appropriate to limit some treatments such as liver transplantation in patients who continue to drink. Here the resources are particularly scarce and continued drinking will reverse the benefit of transplantation. At the other end of the therapeutic spectrum, withholding basic interventions such as fluid resuscitation in patients with gastrointestinal bleeding seems inappropriate. Limiting treatment somewhere between these two extremes may, however, be appropriate. There are no easy answers, but we need to develop clearer guidelines and a more consistent approach so that a patient's outcome does not depend on where and which day they are admitted.

Competing interests: None declared.

1 Chick J, Howlett H, Morgan MY, Ritson B. United Kingdom multicentre acamprosate study (UKMAS): a 6-month prospective study of acamprosate versus placebo in preventing relapse after withdrawal from alcohol. Alcohol Alcohol 2000;35:176-87.

2 Comar KM, Sanyal AJ. Portal hypertensive bleeding. Gastroenterol Clin North Am 2003;32:1079-105.

(Accepted 30 September 2005) 